\title{
EFFECTIVENESS OF REPRODUCTIVE HEALTH EDUCATION AMONG RURAL ADOLESCENT GIRLS: A SCHOOL BASED INTERVENTION STUDY IN UDUPI TALUK, KARNATAKA
}

\author{
R. S. P. RAO, A. LENA, N. S. NAIR', V. KAMATH, A. KAMATH
}

\section{ABSTRACT}

BACKGROUND: Adolescence is the most important and sensitive period of one's life ${ }^{[1]}$. According to the World Health Organization (WHO) Expert Committee, adolescence is defined as the period between 10 and 19 years, the second decade of life. OBJ ECTIVE: To determine the effectiveness of an educational intervention program on knowledge of reproductive health among adolescent girls. SETTINGS AND DESIGN: This educational intervention study was carried out over a period of one year. A total of 791 rural girls in the age group 16-19 years were randomly selected from coastal villages in Udupi District, Karnataka. MATERIALS AND METHODS: Adolescent girls were educated regarding reproductive health and their awareness levels were evaluated immediately following intervention. STATISTCAL ANALYSIS: Data was tabulated and analyzed using SPSS version 11.0 for Windows. Findings were described in terms of proportions and percentages. Chi square test was used to test the effect of the intervention. RESULTS: A significant increase in overall knowledge after the intervention (from 14.4 to $68 \%, \mathrm{P}$ $<0.01$ ) was observed regarding contraception. Knowledge regarding ovulation, first sign of pregnancy and fertilization improved by $37.2 \%(95 \% \mathrm{Cl}=(35.2,39.2), \mathrm{P}<$ $0.001)$. Knowledge regarding the importance of diet during pregnancy improved from 66 to $95 \%$ following the intervention. CONCLUSION: This study clearly showed that an educational intervention program can bring about a desirable change in knowledge among adolescent girls regarding reproductive health.

Key words: Adolescents, effectiveness, health education program, knowledge

\section{INTRODUCTION}

Adolescents comprise $20 \%$ of the world's total population. ${ }^{[1]}$ Out of 1.2 billion adolescents

Department of Community Medicine, Kasturba Medical College, Manipal, 'Department of Statistics, Manipal University, Manipal, India

\section{Correspondence:}

Dr. Lena A,

Department of Community Medicine,

Kasturba Medical College, Manipal, Karnataka, India- 576104

E-mail: lenamrinal@yahoo.com

DOI: 10.4103/0019-5359.48455 worldwide, about $85 \%$ live in developing countries. ${ }^{[2]}$ In India, there are 190 million adolescents comprising $21 \%$ of India's total population. ${ }^{[3]}$ Adolescent pregnancies constitute $10-15 \%$ of total pregnancies in India. This is largely attributed to early marriage, a culture widely prevalent in the whole of the Indian subcontinent, besides Africa. ${ }^{[4]}$

Among adolescents, girls are particularly vulnerable, not only because they are more likely to be coerced invariably for unprotected 
sex than boys, but they are more susceptible biologically to sexually transmitted diseases (STDs), including HIV infection. Inequality between the sexes makes girls more vulnerable to violence and sexual abuse. Their long-term economic potential is reduced still further by early childbearing. ${ }^{[5]}$

Thus, in order to lead healthy, responsible and fulfilling lives, and protect themselves from reproductive health problems, young people need to be knowledgeable about themselves and the people they relate to, and need sound information about the physical, psychological and social changes that take place through childhood and adolescence. ${ }^{[6]}$

Consistent with the economic and social changes in the country, girls in India are increasingly marrying late with a subsequent increase in the age at first childbirth. This has made the risk of premarital sex higher than ever before. Among the several options available in India, creating awareness among adolescents appears to be an important prerequisite.

This study was thus carried out to assess the knowledge of adolescent girls regarding menstruation, pregnancy and contraception, to design, develop and implement a health education program for adolescent girls and study the effect of a health education program in terms of improvement of knowledge.

\section{MATERIALS AND METHODS}

This was an intervention study carried out in the year 2003-04 among the rural colleges of Udupi Taluk, Karnataka. The study population included girls from pre-university colleges (synonymous to $11^{\text {th }}$ and $12^{\text {th }}$ standard of conventional $10+2$ schools). The sampling design used for the study was stratified cluster sampling. Students were stratified on the basis of the year (first or second of pre-university) and course (i.e., arts, commerce and science). There were several divisions under each course. Each division in a stratum was taken as a cluster. Thus a total of 126 clusters belonging to 29 colleges of Udupi Taluk was the sampling frame. Based on the experience gained from the pilot study, a cluster of 40-60 students was found to be feasible for intervention. With this criterion, 34 clusters were found to be eligible for the study. Of these, 16 clusters were randomly selected. A sample size of 391 was calculated taking into consideration a dropout rate of $10 \%$ and design effect of two. However, considering the feasibility and the beneficial effect of the intervention, a total of 791 students were included in the study.

Willingness to participate in the study was obtained by a verbal consent from the students after explaining the objectives of the study. To ensure confidentiality, students were asked not to furnish their names.

\section{Pre-test}

A total of 791 students participated in the pretest assessment. A pre-tested questionnaire was administered which included baseline characteristics of the study population, with questions related to knowledge on menstruation, menstrual hygiene regarding pregnancy, antenatal care and contraception.

\section{Interventions}

A comprehensive health education program was organized in five sessions for this group of students. Each session was of two hours 
duration conducted on five consecutive days. The training methods included a didactic lecture followed by interactive sessions. The topics included were menstruation, menstrual hygiene, pregnancy, antenatal care and various methods of contraception. Audio visual aids such as chalk and blackboard, charts, posters and video films were also used. The education was followed by an interactive session with the students to clarify doubts.

\section{Post-test}

The effect of the intervention was evaluated immediately following intervention with a posttest questionnaire.

The data was analyzed using the Statistical Package for Social Sciences (SPSS) Version 11. The data has been analyzed using proportions and percentages, and chi square test was used to test the improvement in knowledge.

\section{RESULTS}

Of the 791 students enrolled into the study, 779

Table 1: Age distribution of the students

\begin{tabular}{lcc}
\hline Age (years) & No. & (\%) \\
\hline $15-15.9$ & 61 & 7.7 \\
$16-16.9$ & 336 & 42.5 \\
$17-17.9$ & 354 & 44.7 \\
$18-18.9$ & 38 & 4.8 \\
$19-19.9$ & 2 & 0.3 \\
\hline
\end{tabular}

were available for immediate post-test. Around $87 \%$ of the students were in the age group of 16-17 years with a mean of 16.47 years [Table 1]. Around $83 \%$ of the students were Hindus. A majority of the parents were literate.

Table 2 shows that the students had a good knowledge regarding age at first menses and genital hygiene at pre-test. Almost half the students were not aware of the term ovulation. Their knowledge regarding menstruation and menstrual hygiene improved significantly from 77.2 to $95.6 \%$ and 91.8 to $100 \%$ respectively after intervention $(P<0.0001)$.

It is seen from Table 3 that, though most of the students (98\%) were aware of the importance of regular antenatal checkups, their knowledge regarding importance of diet, rest and exercise during pregnancy was poor (66\%). Missed period as the first sign pregnancy was not known to around $40 \%$ of the students. The intervention significantly improved participants' knowledge by a margin of $35.3 \%(95 \% \mathrm{Cl}=$ (33.4, 37.2).

Table 4 shows the awareness of students regarding availability of different methods of contraception. It was observed that their knowledge was poor during pre-test and remarkable improvement was noted following intervention $(P<0.0001)$. It was observed

Table 2: Knowledge related to menstruation and menstrual hygiene

\begin{tabular}{|c|c|c|c|c|}
\hline \multirow[t]{2}{*}{ Questions } & \multicolumn{2}{|c|}{ Pre-test $(n=779)$} & \multicolumn{2}{|c|}{ Post-test $(n=791)$} \\
\hline & No. & $\%$ & No. & $\%$ \\
\hline Usual age at which girl has menses for the first time (9-16years) & 756 & 95.6 & 779 & $100^{\mathrm{a}}$ \\
\hline The usual interval between two menstrual cycles ( 1 month) & 611 & 77.2 & 715 & $91.8^{\mathrm{a}}$ \\
\hline Initially menses are irregular and quantity of bleeding varies however, & & & & \\
\hline Ovulation is release of matured egg from the ovary (True) & $\begin{array}{l}701 \\
368\end{array}$ & $\begin{array}{l}88.6 \\
46.5\end{array}$ & $\begin{array}{l}765 \\
752\end{array}$ & $\begin{array}{l}98.2^{\mathrm{d}} \\
96.5^{\mathrm{a}}\end{array}$ \\
\hline $\begin{array}{l}\text { One should use clean cloth/sanitary napkin and change them regularly } \\
\text { to maintain genital hygiene. (Agree) }\end{array}$ & 714 & 90.3 & 703 & 90.2 \\
\hline
\end{tabular}

${ }^{a}$ Comparison of pre-test and post-test knowledge improved significantly $(P<0.05)$ 
Table 3: Knowledge related to antenatal care

\begin{tabular}{|c|c|c|c|c|}
\hline \multirow[t]{2}{*}{ Questions } & \multicolumn{2}{|c|}{ Pre-test $(n=779)$} & \multicolumn{2}{|c|}{ Post-test $(n=791)$} \\
\hline & No. & $\%$ & No. & $\%$ \\
\hline The first sign of pregnancy is (missed period) & 484 & 61.2 & 752 & $96.5^{\mathrm{a}}$ \\
\hline Fusion of the sperm with the ovum is called (fertilization) & 431 & 54.5 & 714 & $91.7^{\mathrm{a}}$ \\
\hline Regular antenatal checkup is essential during pregnancy (Agree) & 776 & 98.1 & 773 & 99.2 \\
\hline Proper diet, rest and exercise during pregnancy is essential (Agree) & 522 & 66.0 & 740 & $95.0^{\mathrm{a}}$ \\
\hline
\end{tabular}

${ }^{a}$ Comparison of pre-test and post-test knowledge improved significantly $(P<0.05)$

Table 4: Knowledge regarding contraception

\begin{tabular}{lccccc}
\hline Questions & \multicolumn{2}{c}{ Pre-test $(n=779)$} & & \multicolumn{2}{c}{ Post-test $(n=791)$} \\
\cline { 2 - 3 } \cline { 5 - 6 } & No. & $\%$ & & No. & $\%$ \\
\hline Oral contraceptives & 277 & 35.0 & & 699 & $89.7^{\mathrm{a}}$ \\
Condoms & 146 & 18.5 & & 669 & $85.9^{\mathrm{a}}$ \\
IUCD & 88 & 11.1 & & 661 & $84.9^{\mathrm{a}}$ \\
Tubectomy & 99 & 12.5 & & 467 & $59.9^{\mathrm{a}}$ \\
Vasectomy & 15 & 1.9 & & 55 & $7.1^{\mathrm{a}}$ \\
Do not know & 422 & 53.4 & & 32 & $4.1^{\mathrm{a}}$ \\
\hline
\end{tabular}

${ }^{a}$ Comparison of pre-test and post-test knowledge improved significantly $(P<0.05)$

that their knowledge regarding the temporary methods improved to a great extent after intervention with a range of 84 to $89 \%$ for various methods of contraception as compared to the pretest awareness levels of 11.1 to $35 \%$.

Knowledge that "small family norm" refers to a family with two children was known to $98 \%$ of the students. Health personnel were the most preferred option for imparting sex education (95\%).

\section{DISCUSSION}

This study examined the effect of health education on students' knowledge and attitudes towards reproductive health. Greater changes were observed regarding knowledge as compared to attitudes.

Various studies have shown the effectiveness of interventions in increasing knowledge of reproductive health. ${ }^{[7-10]}$ Studies conducted in developed countries have also shown that girls have knowledge and use contraceptives to prevent unwanted pregnancies. ${ }^{[11]}$ The present study indicated that girls had reasonably good knowledge regarding certain aspects of reproductive health. This is probably due to the better literacy rate that is seen in this area, in spite of its being rural.

Studies conducted in India revealed poor knowledge among girls regarding contraception and the present study concurs with these findings. ${ }^{[12-14]}$ Similar findings have been noted in other developing countries as well. ${ }^{[11,15,16]}$ Although the effectiveness of health education remains controversial, it nevertheless has its merits. Unintentionally it creates an increased awareness among adolescent girls, empowering them to take care of their own health as well as protect themselves from possible reproductive health problems.

\section{CONCLUSION}

The results of this study suggest that health education can improve adolescent girls' knowledge of reproductive health. Such educational programs must be given due importance to safeguard the health of adolescent girls.

\section{ACKNOWLEDGMENT}

To the teachers and students for their cooperation. 


\section{REFERENCES}

1. INCLEN International Clinic Epidemiology Network. 1998-2001. [last accessed on 2003 Jun 2]. Available from: http:// www. inclen.org.

2. Improving adolescent health and development. The second decade WHO/FRH/ADH/98.18; p. 2.

3. Adolescence: Development and Obstacles. Adolescence, Resource and Reference Centre, Psychosocial aspects of AIDS CMC Vellore. Health Dialogue 2002;28:1-3.

4. Bhatia BD, Chandra K. Adolescent mother and an unprepared child. Indian J Mat Child Health 1993;4:67-70.

5. "Coming of Age" from facts to action for adolescent sexual and reproductive Health", WHO/FRH/ ADH/97.18, Geneva: 1997. p. 4.

6. Adolescence the Critical Phase, The Challenges and The Potential. World Health Organization; 1997.

7. Shetty $P$, Kowli S. Family life education for nonschool going adolescents: An experiment in an urban slum. J Fam Welfare 2001;47:51-8.

8. Mandal K. Teaching adolescent school girls about menstrual hygiene. Indian J Nursing Midwifery 1998;1:19-26.

9. Parwej S, Kumar R, Walia I, Aggarwal AK. Reproductive health education intervention trial. Indian J Pediatr 2005;72:287-91.

10. Russell-Brown P, Rice JC, Hector O, Bertrand
JT. The effect of sex education on teenagers in St. Kitts and Nevis. Bull Pan Am Health Organ 1992;26:67-79.

11. Lema VM, Hassan MA. Knowledge of sexually transmitted diseases, HIV infection and AIDS among sexually active adolescents in Nairbi, Kenya and its relationship to their sexual behaviour and contraception. East Afr Med J 1994;71:122-8.

12. Gupta N, Mathur AK, Singh MP, Saxena NC. Reproductive health awareness of schoolgoing unmarried adolescents. Indian J Pediatr 2004;71:797-801.

13. Kumar R, Raizada A, Agarwal AK, Kaur M. Adolescent behaviour regarding reproductive health. Indian J Pediatr 2000;67:877-82.

14. Bhatia V, Swamy HM. Fertility Control methods: Knowledge of adolescent girls in schools of Chandigarh. Ind J Med Sci 2000;54342-6.

15. Kibret M. Knowledge, attitude and practice on reproductive health among high school students in Bahir Dar, Ethiopia. Afr J Reprod Health 2003;7:39-45.

16. Buga GA, Amoko DH, Ncayiyana DJ. Sexual behaviour, contraceptive practice and reproductive health among school adolescents in rural Transkei. S Afr Med J 1996;86:523-7.

Source of Support: Nil, Conflict of Interest: None declared. 